\title{
Educational placements for children who are ventilator assisted
}

Jones, David E;Clatterbuck, Chris C;Marquis, Janet;Turnbull, H Rutherford, III;Moberly, Rebecca L Exceptional Children; Fall 1996; 63, 1; ProQuest Research Library pg. 47

\section{Educational Placements for Children Who Are Ventilator Assisted}

\author{
DAVID E. JONES \\ CHRIS C. CLATTERBUCK \\ JANET MARQUIS \\ H. RUTHERFORD TURNBULL III \\ REBECCA L. MOBERLY \\ The University of Kansas
}

aвstract: As mechanical ventilation becomes more portable and home nursing care more available, children who rely on ventilators for life support are leaving hospitals and returning to their homes and schools. The authors surveyed 77 families during 1990-1991 to obtain information on the educational placements of these children and parental satisfaction with services. Interviews were conducted with a subsample of 22 families with differing levels of satisfaction and advocacy. Results suggest that barriers to the integration of these children into school-based programs are attitudinal more than technological. Parent satisfaction with services increased with the number of years the student was placed in school.

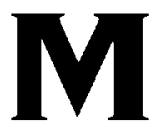
ceting the educational needs of children who are ventilator assisted poses an enormous challenge for parents, educators, and medical personnel. Much of the challenge stems from a lack of policies regarding provision of services to children supported by medical technology. Although the Individuals with Disabilities Education Act (IDEA) ensures educational and related services for students with special needs, its policies were never intended to address all of the education and certainly few of the health-related requirements of children who are chronically ill or technology dependent (Walker \& Jacobs, 1984). Consequently, schools and families must make difficult decisions regarding educational placement and service provision without sufficient guidance and support from IDEA or its regulations. Given the general absence of policy mandates or guidelines, it is not surprising that many school systems refused to admit or inappropriately placed or served children with complex health care needs (U.S. Department of Health and Human Services, 1988). 
Children who are ventilator assisted compose one of several subgroups of students classified as technology dependent (U.S. Department of Health and Human Services, 1988). They require mechanical ventilation to sustain them because of life-threatening respiratory disorders. Etiologies that somerimes necessitate ventilator support include bronchopulmonary dysplasia, neuromuscular disease (e.g., muscular dystrophy), and injuries (e.g., spinal cord injuries or brain stem contusions). As with other children who ate technology dependent, children who are ventilator assisted require ongoing daily care or periodic monitoring by trained personnel (U.S. Department of Health and Human Services).

Until about 15 years ago, most children supported by mechanical ventilation lived in hospitals or long-term care facilities. Major improvements in the portability of ventilator equipment and the increased availability of home nursing support have now made home placements a viable option for many families (Lehr, 1990). Concerns about cost containment have also spurred the transition from hospital to home and community care. One consequence of the shift to home care is that more and more school systems are facing the challenge of providing services to students who are ventilator assisted. The most accurate recent estimace is that there are between 700 and 2,000 children who require ventilator assistance either full time (24-hr continuous support) or part time (U.S. Congress, 1987). The continued refinement and broader application of medical technology suggests that the number of children who are ventilator assisted will continue to grow.

IDEA mandates that children with ventilator support should be classified as "other-health impaired" for IDEA purposes [34 C.F.R. Part 300 , Sec. 300.7 (b)(8)], but national data on these students' placements (U.S. Office of Special Education and Rehabilitation Services, 1993) show that the schools classify them not only into the $\mathrm{OHI}$ category but into other categories as well. Further, educational placement for these children is highly dependent on available resources. These resources may be affected by the child's geographical location, the degree to which services are coordinated (U.S. Congress, 1987), availability of competent staff, attitudes of educational service providers, funding limitations, legal liability, and state and federal educational policy (D. K. Walker, 1987; P. Walker, 1991).

In a study of school and family perspectives on the needs of children with chronic illnesses, Lynch, Lewis, and Murphy (1992) found that parents were generally satisfied with educational programs for their children. Parents, however, underscored the need for educators to better understand the pervasive effects of chronic illness on children's lives. Lynch, Lewis, and Murphy suggested that schools and families have differing concerns and priorities regarding educational services for children with complex health care needs.

Considering all the factors that could affect educational services for children who are technology dependent, little is known about specific influences on educational placement. Without such information, it will be difficult to develop policies and practices responsive to the needs of these students (Palfrey, DiPrete, Walker, Shannon, \& Maroney, 1987).

During the 1990-1991 school year, we collected data on educational placement influences as part of the Technology Support Project at the Beach Center on Families and Disability, the University of Kansas (Barber, Turnbull, \& Murphy, 1989). The purpose of the project was to identify and describe the major factors that affect the provision of educational services to school-aged children who are ventilator assisted. In this arcicle, we summarize what we learned from surveys and interviews with parents, especially as they responded to these questions:

- What types of educational placements and services do these students receive within the school system?

- What factors are considered when determining educational placements?

- What are parents' assessments regarding the adequacy of these placements?

\section{METHOD}

\section{Selection Procedures}

Our first task was to identify a national sample of families with children who are ventilator assisted. Because no registry of these children currently exists, we telephoned 45 states to inquire about 
agencies, hospirals, parent groups, and professional organizations involved in serving these children. We asked agencies or other groups wishing to cooperate in the research to mail a packet of information to each family. A total of 349 packets were mailed to families in 30 states. Each packet included a letter describing the study and inviting parent participation, a letter of support from the agency or group, and a consent card. Parents wishing to participate in the study filled out the consent card and returned the card to us. On receipt of the consent cards, we sent a copy of the questionnaire to the parents who qualified. We included only those parents whose children met the following criteria:

1. The child was served by a public school system or private school (i.e., parochial) in Grades kindergarten through 12 .

2. The child's ventilator use was either full or part time.

3. The child received either home- or schoolbased educational services (children educated within hospitals or other institutional settings were excluded).

A total of 110 consent cards were returned by parents from 27 different states $(110 / 349=$ $31.5 \%$ return rate). Three of these families were excluded (two because the children were too young and one because of the child's death). Of the 107 families who were mailed surveys, 87 returned completed forms $(87 / 107=81 \%$ return rate). Ten surveys were excluded because the children did not meet selection criteria. A total of 77 usable surveys were received from parents from 27 states.

\section{Instrument Development}

Our 51-item questionnaire for parents was organized into seven sections: Issues in service planning (5 items), current programs and related services ( 8 items), educational placement ( 4 items), parent-professional communication and advocacy ( 6 items), provision of school-based services ( 8 items), home-based services ( 4 items), and child and family information (16 items). These sections were based on our comprehensive review of the literature (Condry, 1989).

With respect to educational placement, we asked respondents to (a) describe the educational programs utilized, related services received, and the level of integration experienced by their children during the 1990-1991 school year; (b) provide information on the rationale used to make educational placement decisions and evaluate the adequacy of academic, health care, and therapy services; (c) report the number of home-based educational service hours received by students and describe current or future plans for transition to school; and (d) report demographic information on themselves and their children.

Before distributing the questionnaire, we field-tested drafts with a small group of parents with children who are ventilator assisted and asked a group of special education professionals to review the instrument. We requested parent and professional reviewers to evaluate the questionnaire with respecr to clarity of instructions and ease of use. They determined that the questionnaire required about $1 \mathrm{hr}$ to complete. We published the revised questionnaire in booklet form and mailed it with postage-paid return envelopes to parents identified according to the procedure described previously.

\section{Interview Procedures}

We selected interviewees from among survey respondents. To ensure representativeness, we placed all respondents in groups based on their responses regarding satisfaction with services and whether parents "had to fight" to obtain services. From the selected questions, we classified respondents into four groups:

1. Those who were satisfied with educational services and who did not have to "fight" for such services.

2. Those who were satisfied with services but who did have to "fight" to obtain services.

3. Those who were dissatisfied with services and who had to "fight" to obtain the services presently received.

4. Those respondents with students in homebased education.

Within each group, we stratified the respondents by age of child and then used a randomization procedure to select respondents from each group. We sent 30 invitations to selected 
families to participate in an interview; 22 of these families agreed to participate.

The telephone interviews were approximately $1 \mathrm{hr}$ in length and consisted of a series of closed- and opened-ended questions designed to clarify issues emerging from the surveys and to further define the process of obtaining educational services for children who are ventilator assisted.

\section{RES U LTS}

\section{Characteristics of Respondent Families}

The parent sample had the following characteristics. Most families lived in metropolitan areas $(42 \%)$. Twenty-five percent lived in small cities and $25 \%$ lived in towns, with $9 \%$ living in rural areas. Parents, stepparents, or adoptive parents composed $88 \%$ of the sample; $8 \%$ were foster parents. Of the $4 \%$ who listed "other," most were grandparents who were the primary caregivers. Most respondents were female (95\%).

With respect to the educational status of the main wage-earners, $28 \%$ had 12 years or less of schooling, $21 \%$ had some college experience, $9 \%$ had vocational or associate's degrees, $29 \%$ bachelor's degrees, and another $13 \%$ had graduate degrees. In $83 \%$ of the families, the main wageearners were employed full time. Among the others were part-time employees $(3 \%)$, retirees $(1 \%)$, and unemployed $(8 \%)$. The main wage-earners had a variety of occupations from skilled and technical workers to professional and upper-management personnel. Family income levels were as follows: $\$ 25,000$ or less $(31 \%), \$ 25,000-\$ 50,000$ (40\%), $\$ 50,000-\$ 75,000(17 \%)$, and $\$ 75,000$ or more $(12 \%)$.

\section{Characteristics of Ventilator-Assisted Children}

The sample of ventilator-assisted children had the following characteristics. The majority of children in the study were male (62\%) and Caucasian $(82 \%)$. Most $(79 \%)$ of the sample had reported IQ levels in the normal range.

Because of the many variables involved with this population, it was not possible to identify a "typical" ventilator-assisted student. Table 1 shows a summary of student demographic infor- mation. Information reported in the following section and elsewhere in this article is based on the total sample of ventilator-assisted students, regardless of their current educational setting ( $N=$ 77). In those cases where information relates to students in one specific educational setting (i.e., school-based students or home-based students), the information is noted accordingly.

\section{Home-Versus School-Based Educational Placement}

Of the parents surveyed, $91 \%(n=70)$ of the parents surveyed indicated that their children received educational services in a school-based setting, and $9 \%(n=7)$ reported that their children were served primarily through home-based services. Whereas students primarily receiving home-based services account for only a small portion of the total sample, many students have made use of home-based services sometime during their educational careers. Forty percent of respondents reported that their children received between 1 and 7 years of home-based services at some point during their educational career. In most cases, the duration of these home-based services was between 1 and 2 years.

\section{Educational Placement and Disability Classification}

Of the 77 families surveyed, six respondents were not sure in which educational program(s) their children were enrolled. Thirty-two reported that their children were in a general education program, including 1 home-based student. The remaining 39 reported that their children were in special education programs, including 6 homebased children. Of the 39 students in special education, the largest classification was "orthopedically handicapped" (41\%). Other common classifications were "severely multiply handicapped" (21\%), "other-health impaired" (18\%), "learning disabled" (10\%), and "mentally retarded" and "speech impaired" (5\% each). No respondents listed "emotionally disturbed," "visually impaired," "hearing impaired," or "deaf/blind" as their children's primary special education classification. 
TABLE 1

Characteristics of Ventilator-Assisted Students $(N=77)$

\begin{tabular}{lccc}
\hline Student & Range $(\mathrm{n})$ & Mean $(\%)$ \\
\hline Age & 5 to 20 years & 9.0 years
\end{tabular}

Gender

Male

Female

Race

Caucasian

African American

Native American

Asian American

Not reported

IQ level

Normal

Some degree of cognitive disability

Unknown

Ventilator use

Continuous ( $24 \mathrm{hr}$ per day)

Fewer than $24 \mathrm{hr}$ per day (Ventilator not used during school hours)

Fewer than 24 hr per day (Ventilator used during school hours)

Impact of ventilator on learning

Very little interference with day-to-day learning

Some interference with learning due to unusual episodes or some routine care

Moderate interference with learning due to frequent crises or time-consuming routine care

Severe interference with learning due to the need for special medical care on a nearly continuous basis 


\begin{tabular}{lcc}
\hline Student & Range $(\mathrm{n})$ & Mean $(\%)$ \\
\hline Age & 5 to 20 years & 9.0 years \\
Diagnosis & 32 & 42 \\
Congenital anomalies $^{\mathrm{a}}$ & 16 & 21 \\
Injuries $^{\mathrm{b}}$ & 15 & 19 \\
${\text { Diseases of the nervous system }{ }^{c}}_{\text {Bronchopulmonary dysplasia }}$ & 6 & 8 \\
Other ${ }^{\mathrm{d}}$ & 6 & 8 \\
Not sure or missing & 2 & 3 \\
\hline
\end{tabular}

Note: $75 \%$ of the students in the survey began using a ventilator prior to the age of 5 .

${ }^{a}$ Examples of congenital anomalies include central hypoventilation syndrome, congenital anomalies of the heart, or of the respiratory system, and so forth. ${ }^{b}$ Examples of injuries include spinal cord injury, near drowning, brain-stem contusions, and so forth. ${ }^{C}$ Examples of diseases of the nervous system include Werdnig-Hoffman disease, muscular dystrophy, and so forth. ${ }^{\mathrm{d}}$ Examples of diagnoses that were reported include meningitis, paralyzed diaphragm, and sleep apnea.

\section{Types of Educational Placements}

We made a distinction between type of educational program (i.e., general or special education classification) and the time a child spends in particular educational settings (i.e., educational placement). This distinction was made because a student's educational program does not necessarily describe where the child spends the majority of his or her instructional time. For the 70 schoolbased students, we analyzed data on the child's educational setting-general classroom, special education classroom, or a combination. Two children attending parochial school were considered to be in a general education classroom all or most of the time. Table 2 provides data on the amount of time school-based students with various educational classifications spent in the different classroom settings.

As Table 2 shows, $67 \%$ of the children spend the majority of their time in general classroom settings, although only $44 \%$ are in a general education program. Of the 34 school-based special education students, 15 are in general classrooms all or most of the time. Of the 16 students in special education classrooms all or most of the time, 8 have some degree of cognitive impair- ment, 7 have normal intelligence, and the intellectual ability of 1 special education student was not reported. Three special education students were in special schools.

\section{Hours in School}

For the school-based students, the number of hours in school ranged from 7.5 to $40 \mathrm{hr}$ per week, with one person not responding to this question. Two home-based students also received instruction at school. Of those who responded, approximately $7 \%$ attend school $10 \mathrm{hr}$ or less, and $37 \%$ attend between 11 and $29 \mathrm{hr}$. The remainder $(55 \%)$ attend school for 30 or more hr per week. In addition to their school-based education, $16 \%$ receive between 2 and $10 \mathrm{hr}$ per week of home-based services.

\section{Hours of Instruction}

The average number of educational service hours for home-based students was $7.9 \mathrm{hr}$ per week, with a range of 1 to $20 \mathrm{hr}$ per week. One student attended school for $3 \mathrm{hr}$ per week, and another for $9 \mathrm{hr}$ per week. Of the seven parents with children in home-based education, two believed that their children should attend school in the next 


\begin{tabular}{|c|c|c|c|c|c|c|c|c|}
\hline \multirow[b]{2}{*}{$\begin{array}{l}\text { Educational } \\
\text { Program }\end{array}$} & \multicolumn{2}{|c|}{$\begin{array}{l}\text { General Classroom } \\
\text { (Mostly or Always) }\end{array}$} & \multicolumn{2}{|c|}{$\begin{array}{l}\text { SPED Classroom } \\
\text { (Mostly or Always) }\end{array}$} & \multicolumn{2}{|c|}{ Special School } & \multicolumn{2}{|c|}{ Total } \\
\hline & $\mathrm{n}$ & $\%$ & $\mathrm{n}$ & $\%$ & $\mathrm{n}$ & $\%$ & $\mathrm{n}$ & $\%$ \\
\hline General education & 30 & 43 & 1 & 1 & - & - & 31 & 44 \\
\hline \multicolumn{9}{|l|}{ Special education } \\
\hline SMH & - & - & 5 & 7 & 2 & 3 & 7 & 10 \\
\hline $\mathrm{OH}$ & 9 & 12 & 4 & 6 & 1 & 1 & 14 & 20 \\
\hline $\mathrm{OHI}$ & 3 & 4 & 2 & 3 & - & - & 5 & 7 \\
\hline LD & 2 & 3 & 2 & 3 & - & - & 4 & 6 \\
\hline MR & - & - & 2 & 3 & - & - & 2 & 3 \\
\hline SI & 1 & 1 & 1 & 1 & - & - & 2 & 3 \\
\hline Unknown & 2 & 3 & 3 & 4 & - & - & 5 & 7 \\
\hline Total & 47 & 67 & 20 & 29 & 3 & 4 & 70 & 100 \\
\hline
\end{tabular}

Note: Special education program categories: $\mathrm{SMH}=$ Severe multiple handicaps; $\mathrm{OH}=$ Orthopedic (physical) handicaps; $\mathrm{OHI}=$ Other health impairments; $\mathrm{LD}=$ Learning disabilities; $\mathrm{MR}=$ Mental retardation; $\mathrm{SI}=$ Speech impairments. These categories are those that existed in the 1990-1991 school year, before Individuals with Disabilities Education Act (IDEA) was amended in 1990.

academic year and reported having made plans to facilitate this transition to school. Two respondents reported that they wanted their children to remain in home-based education, and the remaining three were unsure whether a school placement would be appropriate for their children.

\section{Level of Integration}

Parents were also asked to evaluate their children's education in terms of the level of integration. Complete integration was reported only in the general classrooms. Parents whose children were in general classrooms all or most of the time were more likely to be satisfied with their children's current level of integration. Only 7 of the 45 parents $(16 \%)$ wanted more integration, and 1 parent wanted less. On the other hand, parents whose children were in special education classroom all or most of the time reported lower levels of integration. Twenty students were in special ed- ucation classrooms most or all of the time. Eleven respondents $(55 \%)$ reported a desire for more integration. Parents' desire for more integration may be associated with the intellectual ability of their children, although the number of students in this study was too small to be certain. For children with normal intellectual ability who were in special education classrooms all or most of the time, $73 \%$ ( 8 of 11 ) desired more integration. For children with some degree of cognitive disability who were in special education classrooms all or most of the time, only $38 \%$ ( 3 of 8 ) desired more integration.

\section{Factors That Determine Placement}

Placement for ventilator-dependent students appears to be multiply determined. Respondents were asked to indicate the three most important factors used to determine their children's educational placement. Table 3 shows the number of 
TA B LE 3

Important Determinants of Educational Placement

\begin{tabular}{|c|c|c|c|c|}
\hline \multirow[b]{2}{*}{ Determinant of Placement } & \multicolumn{2}{|c|}{ School-Based Students } & \multicolumn{2}{|c|}{ Home-Based Student } \\
\hline & $\mathrm{n}$ & $\%$ & $\mathrm{n}$ & $\%$ \\
\hline Academic needs of child & 56 & 80 & 3 & 34 \\
\hline Socialization/integration needs of child & 53 & 76 & 3 & 43 \\
\hline Health care needs of child & 34 & 49 & 7 & 100 \\
\hline Psychological/emotional needs of child & 18 & 26 & - & - \\
\hline Therapy needs of child & 14 & 20 & 1 & 14 \\
\hline
\end{tabular}

TABLE 4

Parent Evaluations of Schools' Success in Meeting Students Needs (Percentage of Parent Responses)

\begin{tabular}{lccc}
\hline Area of Need & Yes & No & Unsure \\
\hline Academic & 83 & 10 & 7 \\
Health care & 80 & 16 & 4 \\
Socialization & 78 & 17 & 5 \\
Psychological/emotional & 70 & 16 & 14 \\
Therapy & 61 & 36 & 4 \\
\hline
\end{tabular}

parents who listed concern for their children's academic, socialization, health, psychological/emotional, and therapy needs as one of the three most important issues affecting placement. As is evident, academic and socialization needs figure prominently in placement decisions for schoolbased students. For home-based students, health care needs were clearly the most important factor affecting placement decisions. Alternatively stated, health status determines placementplacement is a determinant of inclusion.

\section{Placement Adequacy and Parent Satisfaction}

Eighty-seven percent $(87 \%)$ of parents reported that they agree with their children's placement. While most parents appeared to agree with their children's placement, their individual evaluations of how schools are doing in terms of meeting their children's specific needs vary considerably. Table 4 provides a summary of parents' beliefs regarding the schools' success in meeting student needs with respect to academics, health care, socialization, psychological/emotional health, and therapy. As indicated, parents are generally content with the schools' success in meeting student needs. Parents appear to be most satisfied with the schools' success in the areas of academics, health care, and socialization. They expressed the most dissatisfaction with therapy services.

To investigate whether a relationship exists between parent evaluations of the schools' success in meeting student needs and the length of time the student has been in school, we grouped parent ratings by the students' years in school (i.e., 1-2, $3-5,6+$ years). The results of this analysis suggest that parent evaluations of schools' ability to meet student needs in some areas appear to be associated with the amount of time the student has been in school. Specifically, three apparent relationships were revealed:

1. Parent rating of the schools' ability to meet student academic, socialization, and therapy 
needs were higher for those students who have been in school for 3 or more years.

2. Parent ratings of the schools' ability to meet student health care needs appear to remain stable regardless of the amount of time a child has been in school.

3. Parent ratings of the schools' ability to meet psychological/emotional needs appears to be lower for those students who have been in school for 6 or more years.

\section{DISCUSSION}

\section{General Satisfaction with Placement}

The results of this study indicate that children who are ventilator assisted receive educational placements (school- and home-based) that meet with a high degree of satisfaction from their parents. Overall, parents express the most satisfaction with schools' performance meeting the academic, health care, and socialization needs of students who are ventilator assisted. These findings are consistent with previous research on parent satisfaction with educational services for children with chronic illnesses (Lynch, Lewis, \& Murphy, 1992).

A fairly large number of children with ventilator supports are integrated into general education programs. This fact may challenge the conventional assumption that these children will be less, not more, integrated because their health care needs are so great. Moreover, their integration correlates positively with parental satisfaction, suggesting that the parents of these children prefer the more inclusive program and setting over the less inclusive ones and that the schools themselves are able and willing to comply with IDEA's presumption in favor of more inclusive, less separated, educational placements and programs.

\section{Dissatisfaction with Therapeutic Services}

Overall satisfaction with placement does not mean that these parents were content with all aspects of educational service provision. In fact, parents expressed dissatisfaction with therapy services for their children. In short, parents want more therapy for their children than schools are able to give. Interview data suggest that much of the dissatisfaction with therapy services may result from differing expectations parents and schools have regarding the amount of time and energy schools should expend on related services for children who are ventilator assisted and, by implication, for other students with special health care needs.

\section{Variable Satisfaction Concerning Psychological Needs}

As noted earlier, parents' evaluation of schools' ability to meet student psychological/emotional needs appears to decline for those students who have been in school for more than 6 years. This finding is notable because it is the one area indicated by parents in which schools do not appear to make improvements as the number of years students are in school increases. This finding most likely relates to the developmental needs of these students: Most of the students in this cohort (6+ years in school) were entering adolescence, a stage characterized by increased psychological/emotional needs. Interview data suggest that this stage of development is particularly difficult for students who are supported by ventilator technology. As one parent noted, "The changes (physical and psychological) brought on by the onset of puberty made this time (adolescence) difficult for all my children, but the presence of the ventilator and the constant monitoring by myself or the nursing staff made this time even more difficult for my son."

\section{Increasing Satisfaction Over Time}

Parents' evaluations of schools' ability to meet student academic, socialization, and therapy needs appear to be higher for students who have been in school for 3 or more years. One possible explanation for this result is that as the result of practice, the schools' ability to meet student needs actually increases; this capability is reflected in the parent evaluations. Another plausible explanation for this finding is that over time, parents' ongoing interaction with educators leads to working relationships and even friendships that may contribute to more positive evaluations of the efforts put forth by schools. In either case, these findings offer parents of children supported by ventilators a measure of hope that given time, 
schools do appear to improve in their ability to meet student needs.

\section{Impact of Technology Use and Exceptionality}

The level of medical care required by students who are ventilator assisted is often viewed as a characteristic that distinguishes these children from other students with special health care needs. It is arguable that "ventilator assistance" is indeed a distinction that makes a difference in educational placement. The data here, however, suggest that the distinctiveness of ventilator assistance is only relevant early in the placement process. Once steps have been taken to address health care needs of these students, the distinction of ventilator assistance no longer makes a difference. Interview data suggest that once fears related to the medical equipment or "imminent" death of these students are addressed, the exceptionality of these children becomes less salient. As one parent stated, "I had to show the school that my child was a normal little girl with a breathing problem, who needs an education."

\section{IMPLICATIONS FOR PRACTICE}

The results of this study provide support to Walker's (1991) contention that the barriers to integration of these children with special health care needs are no longer purely technological, but increasingly and constantly attitudinal as well. With foresight and cooperation, plans for the provision of educational services for children who are ventilator assisted can be successfully implemented. The current movement toward inclusion is quite evident with this population, given the great majority who receive school-based services. This finding should be encouraging to other parents who desire that their children who are chronically ill or dependent on medical technology be placed in a school setting.

Placement is a complicated issue that is not determined by any one factor. Academic requirements, socialization, emotional and psychological needs, therapy availability, and health care concerns are all considered when educators and parents make decisions about placement. Continued effort to work together does pay off, because satisfaction increases with years placed in school.
These relationships are valuable and should be cultivated; they serve to form the groundwork for future decisions about the education of children who need ventilator assistance and who have other chronic health issues.

\section{REFERENCES}

Barber, P. A., Turnbull, H. R., \& Murphy, D. (1989). Technology Support Project: An evaluation of family and LEA decisions regarding the appropriate placement of children with technology support. In Beach Center on Families and Disability, The University of Kansas, Proposal for a rehabilitation research and training center on improving the functioning of families who have members with disabilities (pp. 20-29), (NIDRR Grant No. H133B80046.) Lawrence: Author.

Condry, S. (1989). Topics concerning children who are technology supported and their families: A literature review. Lawrence: The University of Kansas, Beach Center on Families and Disability. (ERIC Document Reproduction Service No. ED 321 442)

Individuals with Disabilitics Act, 34 C.F.R. Part 300, Sec. 300.7 (b)(8).

Lehr, D. H. (1990). Providing education to students with complex health care needs. Focus on Exceptional Children, 22(7), 1-10.

Lynch, E. W., Lewis, R. B., \& Murphy, D. S. (1992). Educational services for children with chronic illnesses: Perspectives of educators and families. Exceptional Children, 59, 210-220.

Palfrey, S. J., DiPrete, L., Walker, D., Shannon, K., \& Maroney, E. (1987). School children dependent on medical technology. Rehabilitation Research Review. Washington, DC: The Catholic University of America.

U.S. Congress, Office of Technology Assessment. (1987). Technology dependent children: Hospital v. home care-A technical memorandum (OTA-TM-H-38). Washington, DC: U.S. Government Printing Office. (ERIC Document Reproduction Service No. 303 949)

U.S. Department of Health and Human Services, Health Care Financing Administration. (1988). Report of the Task Force on Technology-Dependent Children: Fostering home and community-based care for technology-dependent children (HCFA Pub. No. 88-02171). Washington, DC: U.S. Government Printing Office.

U.S. Office of Special Education and Rehabilitation Services, Division of Innovation and Development. (1993). To assure the free appropriate public education of all children with disabilities: Fifteenth annual report to Congress on the implementation of The Individuals with 
Disabilities Education Act. U.S. Department of Education. Washington, DC: U.S. Government Printing Office. (ERIC Document Reproduction Service No. ED 363058 )

Walker, D. K. (1987). Chronically ill children in schools: Programmatic and policy directions for the future. Rheumatic Diseases of Childhood, 13(1), 113-121.

Walker, D. K., \& Jacobs, F. H. (1984). Chronically ill children in school. Peabody Journal of Education, 61(2), 28-74.

Walker, P. (1991). Where there is a way, there is not always a will: Technology, public policy, and the school integration of children who are technology-assisted. Children's Health Care, 20(2), 68-74.
ABOUTTHEAUTHORS

DAVID E. Jones, Project Director; CHRIS C. CLATTERBUCK, Research Assistant; JANET MARQUIS, Assistant Director/Research; H. RUTHERFORD TURNBULL II (CEC \# 665), Co-Director; and REBECCA L. MOBERLY, Research Assistant, Beach Center on Families and Disability, The University of Kansas, Lawrence.

Address correspondence to Rebecca L. Moberly, Beach Center on Families and Disability, 3111 Haworth Hall, University of Kansas, Lawrence, KS 66045 (E-mail: rebecca@dole.lsi.ukans.edu)

Manuscript received February 1995; revision accepted October 1995.

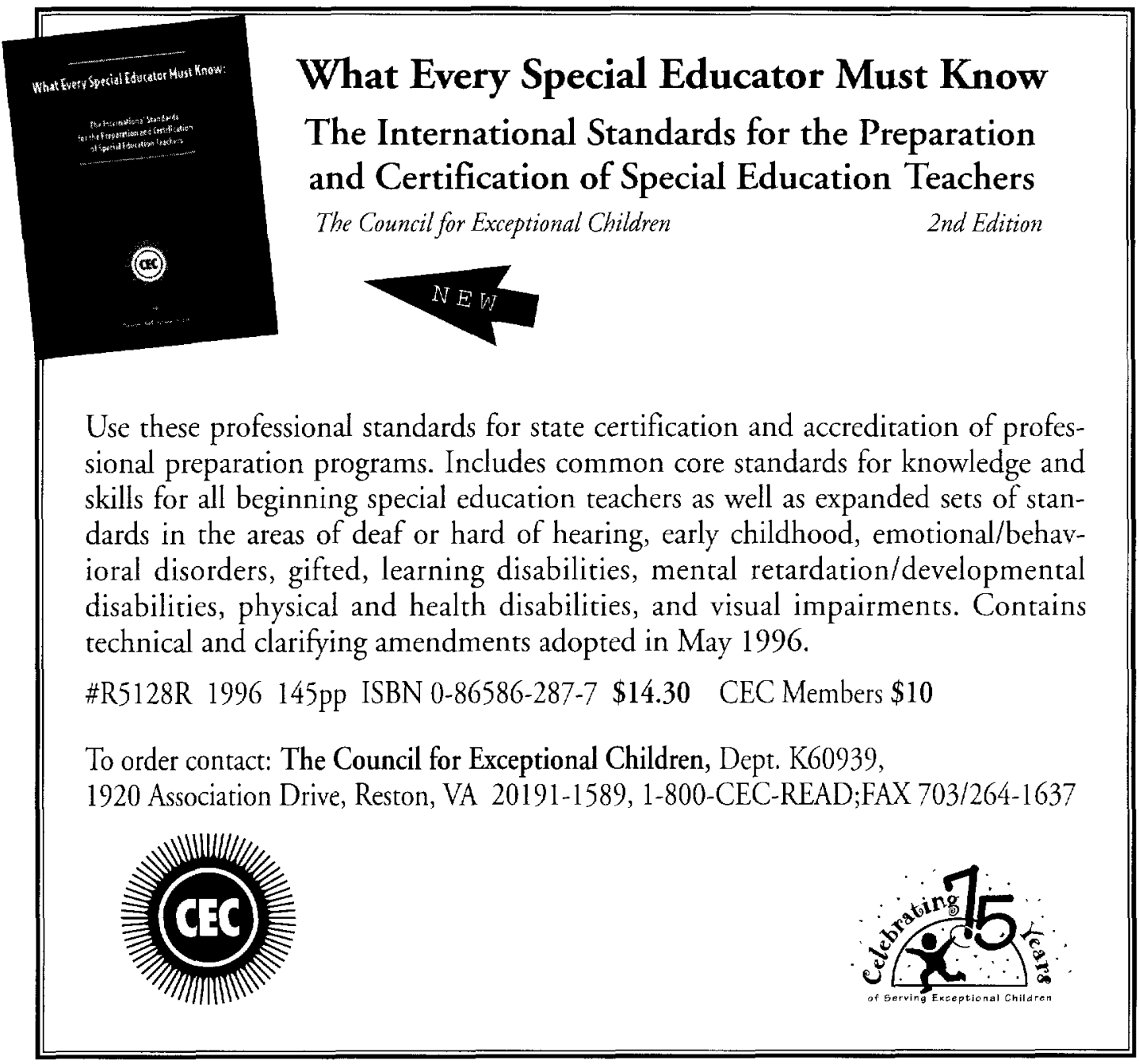

